\title{
Prediction Model of Life Span Degradation under Sulfate Attack Regarding Diffusion Rate by Amount of Sulfate Ions in Seawater
}

\author{
Hojae Lee, Myung-Sug Cho, Jong-Suk Lee, and Do-Gyeum Kim
}

\begin{abstract}
Sulfate attack is one of the most damaging degradation mechanisms that can be accelerated by the increase of the internal stress due to filling the void within concrete with chemical products of gypsum and ettringite and subsequent expansion causes spalling and exfoliation of the concrete. As a result of occurring molecular diffusion, the diffusion coefficient of sulfate ion has played an important factor in existing empirical and mathematical models for its large impact on the extent of the attack. In this study, the expansion and diffusion coefficient are presented to represent a prediction model of life span degradation and a model equation of sulfate attack based on the mechanistic model is proposed.
\end{abstract}

Index Terms-Concrete, sulfate attack, diffusion, prediction model.

\section{INTRODUCTION}

Life span degradation of concrete due to sulfate attack causes penetration of sulfate into the inside of concrete and expansion reaction, and the subsequent expansive stress formed from the reaction leads to cracking of the concrete[1]-[3]. Cracking can significantly increase both the diffusion rate and hydraulic flow rate and in turn accelerate further degradation. Damage to concrete due to the sulfate attack proceeds from the surface of concrete and its damage extent can be expressed as a function of the depth of attack or the amount of expansion by the attack and the progress rate[4]. Accordingly, in this study, an integrated modeling approach is developed to derive a model for predicting the life span degradation incorporating all three of the essential phenomena mentioned above [5]-[7].

Several models have been presented in order to predict the life span degradation due to sulfate attack. There, theoretical models are based only on the penetration depth to predict the life span, disregarding the formulation conditions occurring in concrete under external attack from chemically aggressive environments. However, recent studies indicate the sulfate attack to concrete appeared caused by expansive stress as a result of chemical reaction and the progress rate of degradation is proportional to age. Therefore, the previous results are reflected in the prediction model of life span

Manuscript received January 7, 2013; revised March 5, 2013.

Hojae Lee is with the Structural Engineering Research Division, Korea Institute of Construction Technology, South Korea (e-mail: h.lee@kict.re.kr)

Myung-Sug Cho is with the Plant Construction \& Engineering Laboratory, KHNP Central Research Institute, Korea Hydro \& Nuclear Power Co., LTD, South Korea (e-mail: concrete@khnp.co.kr)

Jong-Suk Lee and Dogyeum Kim are with the Structural Engineering Research Division, Korea Institute of Construction Technology, South Korea (e-mail: jslee@kict.re.kr, dgkim@kict.re.kr) degradation from sulfate attack in our study. Also, in this study, conducting experiments with the formulation used in concrete structures, impact of each factor on the rate of sulfate attack is derived and reflected to our prediction model or used as data to evaluate the resulting prediction model of life span degradation due to sulfate attack.

\section{REVIEW OF MODELS}

\section{A. Emperical Model}

Atkinson \& Hearne (1984) - Atkinson \& Hearne's empirical model has employed data from the Northwick Park study, Harrison and Teychenne (1981) conducted, and used the concentration of sulfide and $\mathrm{C}_{3} \mathrm{~A}$ of cement as factors to be considered [8]-[9]. In the model, they assumed that the depth of attack is linearly related to time and the rate of attack of concrete is proportional to both the concentration of sulfate and the amount of $\mathrm{C}_{3} \mathrm{~A}$. From the experimental results, it has shown that the amount of cement loss of the specimen deposited in $0.19 \mathrm{M} \mathrm{Na}_{2} \mathrm{SO}_{4}$ for 5 years was $42 \mathrm{~mm}$ and the attack depth of $\mathrm{MgSO}_{4}$ was about 2 times larger than that of $\mathrm{Na}_{2} \mathrm{SO}_{4}$. Developed from these experimental results, a model equation was given by equation (1), based on Ordinary Portland Cement (OPC) in which the amount of $\mathrm{C}_{3} \mathrm{~A}$ was $8 \%$.

$$
\begin{aligned}
x & =\frac{4.2}{5} \cdot \frac{C_{S}}{8} \cdot \frac{\left(\mathrm{Mg}^{2+}+S_{4}^{2-}\right)}{0.19} \cdot t \\
& =0.55 C_{S}\left(\mathrm{Mg}^{2+}+S O_{4}^{2-}\right) \cdot t
\end{aligned}
$$

where

$x$ : depth of attack (cm)

Cs: amount of $\mathrm{C}_{3} \mathrm{~A}$ in cement $(\%)$

$\mathrm{Mg}^{2+}, \mathrm{SO}_{4}{ }^{2-}$ : concentration of sulfate ( $\mathrm{mol} / \ell$ )

$t$ : time(year)

Shuman(1989) - As the empirical model has been basis for many models, Shuman's model was derived by coupling the diffusion coefficient with the empirical model and applied to Barrier code, where the concentration of sulfide, $\mathrm{C}_{3} \mathrm{~A}$ of cement, and diffusion coefficient of sulfide were considered as factors. In the model, the rate of attack was assumed to be proportional to the diffusion coefficient and the diffusion coefficient of concrete specimen in a laboratory was fixed at $3 \times 10^{-7} \mathrm{~cm}^{2} / \mathrm{s}$.

$$
x=1.86 \cdot 10^{6} C_{S}\left(M^{2+}+S O_{4}^{2-}\right) D_{i} t
$$

where $D_{i}$ : diffusion coefficient of internal concrete $\left(\mathrm{cm}^{2} / \mathrm{s}\right)$ 
TABLE I: ANALYSIS OF FACTORS TO BE CONSIDERED

\begin{tabular}{|l|c|c|c|c|}
\hline \multirow{2}{*}{ Researchers } & Year & \multicolumn{3}{|c|}{ Factors to be considered } \\
\cline { 3 - 5 } & $\begin{array}{c}\text { Concentration of } \\
\text { sulfide }\end{array}$ & $\begin{array}{c}\text { Diffusion } \\
\text { of sulfide }\end{array}$ & $\begin{array}{c}\text { Amount } \\
\text { of } \mathrm{C}_{3} \mathrm{~A}\end{array}$ \\
\hline $\begin{array}{l}\text { Atkinson \& } \\
\text { Hearne }\end{array}$ & 1984 & $\bigcirc$ & $\times$ & $\bigcirc$ \\
\hline Shuman & 1989 & $\bigcirc$ & $\bigcirc$ & $\bigcirc$ \\
\hline
\end{tabular}

However, relationship in the empirical model between the depth of attack and various influencing factors has fundamental limitations in, especially, the case of exceeding acceptable levels at which many researchers assumed for their models [10], [11]. Therefore, disregarding of using admixture and additive in the experiment, the reliability of the suggested model has decreased. Despite these limitations, however, the model can provide an easy and convenient way to predict the resistance to sulfate attack.

\section{B. Mathematical Model}

Rasmuson (Shrinking Core Model, 1987) - Shrinkage Core model can be applied when boundary condition changes constantly, and mass transport rate of the boundary appears to be much slower compared to the transport rate [12]-[13]. As the change of the boundary condition shows slow progress, transport processes of Sulfide ions can be thought to be near steady state or stationary state leading to be considered as steady state. Sulfate attack progresses by penetrating sulfate ions into internal concrete body from concrete surface under influence of external environment, usually by diffusion. On the boundary layers sulfate ions reacts with hydration products of $\mathrm{C}_{3} \mathrm{~A}$ to generate insoluble substances such as ettringite. For the transport equation of sulfide ions, stationary state is assumed to estimate the rate at which affected zone by the sulfide keeps transferring into the interior of concrete body

Reaction pattern and transfer of sulfate ions are shown as below.

- Reaction patterns.

$$
\mathrm{SO}_{4}^{2-}+\mathrm{X}^{2+} \Rightarrow \mathrm{XSO}_{4}^{2-}
$$

Transport of sulfate ions

$$
N=-D_{i} \frac{C_{o}}{x}
$$

Equation (3) shows that the degradation zone affected by sulfate is proportional to the mass transport rate of sulfate ions and is in inversely relationship with the $\mathrm{C}_{3} \mathrm{~A}$ concentration of concrete.

$$
\begin{gathered}
\frac{d x}{d t}=-\frac{N}{C_{S}}=\frac{D_{i} C_{o}}{C_{S} x} \\
x=\left(\frac{2 D_{i} C_{0}}{C_{S}} \cdot t\right)^{1 / 2}
\end{gathered}
$$

where

$C_{s}$ : amount of $\mathrm{C}_{3} \mathrm{~A}$ in concrete (moles $\left./ \mathrm{cm}^{3}\right)$

$C_{\mathrm{o}}$ : concentration of sulfate $\left(\right.$ moles $/ \mathrm{cm}^{3}$ )

$x$ : distance $(\mathrm{cm})$

$D_{i}$ : internal diffusion coefficient $\left(\mathrm{cm}^{2} / \mathrm{s}\right)$
$N$ : molar flux $\left[\right.$ moles $\left./\left(\mathrm{cm}^{2} / \mathrm{s}\right)\right]$

$t$ : time (s)

In this model, contrary to the experimentally proven results that increase of the amount of $\mathrm{C}_{3} \mathrm{~A}$ that is included in concrete, also accelerates the sulfate attack, sulfide erosion is shown to decrease depending on the increase of $\mathrm{C}_{3} \mathrm{~A}$. In addition, the erosion rate appears as $t^{1 / 2}$ for the time $t$ as a result of diffusion.

Atkinson \& Hearne (Mechanistic Model, 1990) - The mechanistic model of Atkinson \& Hearne represents kinetic response (ettringite coagulation) as a relationship between the spalling of concrete and the degradation rate over time. The model can be obtained from calculating data through laboratory experiments and expresses the process of attack by sulfide in the transport process of delivery and absorption. It also uses time order as empirical model.

Also, according to this model, sulfate ions cause degradation in concrete through the following 3 steps.

- Penetration of sulfate ions into internal concrete is dominated by diffusion.

- Sulfate ions expand reacting with hydrates containing aluminum inside concrete.

- Expansion pressure occurring inside concrete causes stress, cracks, spalling in concrete.

The process of attack appears differently depending on the chemical composition of concrete, the mass transport rate of sulfate ions and reaction rate. The thickness of concrete layer detached by the reaction and the time it takes to takes off the layer also can be calculated by the following equation:

$$
\begin{gathered}
x_{\text {spall }}=\frac{2 \alpha \gamma(1-v)}{E\left(B C_{E}\right)^{2}} \\
t_{\text {spall }}=\frac{X_{\text {spall }}^{2} C_{E}}{2 D_{i} C_{0}}
\end{gathered}
$$

The resulting degradation rate of concrete by sulfate ions is given by equation (4)

$$
R=\frac{X_{\text {spall }}}{t_{\text {spall }}}=\frac{E B^{2} c_{0} C_{E} D_{i}}{\alpha \gamma(1-v)}
$$

where ,

$c_{k}$ : concentration of sulfate in kinetics experiments $\left(\mathrm{mol} / \mathrm{m}^{3}\right)$

$c_{o}$ : concentration of sulfate in solution $\left(\mathrm{mol} / \mathrm{m}^{3}\right)$

$C_{E}$ : concentration of sulfate reacting to ettringite $\left(\mathrm{mol} / \mathrm{m}^{3}\right)$

$D_{i}$ : diffusion coefficient of sulfate ions in concrete $\left(\mathrm{m}^{2} / \mathrm{s}\right)$

$E$ : elastic modulus (20GPa)

$m$ : amount of sulfate reacting with cement $(\mathrm{mol} / \mathrm{kg})$

$m_{e}$ : value of $\mathrm{m}$ to react completely $(\mathrm{mol} / \mathrm{kg})$

OPC: 1.24 , V-Cement: 0.07

$m_{\mathrm{o}}$ : constant for $\mathrm{m}, \mathrm{OPC}: 0.32, \mathrm{~V}-\mathrm{Cement}: 0.16$

$R$ : degradation rate of concrete by sulfate ions

$t_{r}$ : time it takes to react (s),OPC: 3577, V-Cement: 1555

$\alpha$ : roughness factor of the area occurring degradation (assumed 1.0)

$B:$ stress of $1 \mathrm{~mol}$ sulfate to react in $1 \mathrm{~m} 3(1.8 \times$ 
$\left.10-6 \mathrm{~m}^{3} / \mathrm{mol}\right)$

$\gamma$ : energy required to destroy concrete surface $\left(10 \mathrm{~J} / \mathrm{m}^{2}\right)$

$v$ : Poisson ratio $(0.3)$

\section{Comparative Analysis}

Although the empirical model provides an easy and convenient way, there are fundamental limitations in relationship between the depth of attack and various influencing factors, especially, in the case of exceeding acceptable levels at which many researchers assumed for their models, which can cause significant decrease in reliability for the model

Atkinson \& Hearne's empirical model was configured by considering only concentration of $\mathrm{C}_{3} \mathrm{~A}, \mathrm{Mg}$, and molar concentration of $\mathrm{SO}_{4}$ as factors to be considered not even reflecting other characteristics such as the intensity or diffusion coefficient of concrete, which may regard the model unreliable.

In the Shrinking Core Model, contrary to the empirical data in the field and other prediction models for sulfate attack, the rate of sulfate attack is shown to decrease depending on the increase of $\mathrm{C}_{3} \mathrm{~A}$.

While the Shrinking Core Model regards the rate of sulfate attack proportional to $\mathrm{t}^{1 / 2}$ for the time $\mathrm{t}$, the empirical model and mechanistic model express the rate as linear relation to the time $\mathrm{t}$.

The mechanistic model evaluates the elapsed time and the spalling of concrete surface due to expansion pressure considering the expansion occurred by sulfate ions in concrete.

\section{CONFiguration of Prediction MOdel of LifE Span DEGRADATION}

\section{A. Formulation of Basic Model}

In order to estimate the sulfate attack, the degradation depth by sulfate is derived from the mechanistic model of Atkinson-Hearne. As the depth of sulfate attack can be predicted from the Atkinson-Hearne model, covered concrete penetrated by sulfate is assumed to have complete loss of its performance. As the transport characteristics are much larger for soil or seawater compared to concrete, external boundary conditions of concrete are moved to the depth at which sulfate attack advances, resulting in creating new boundary conditions. In other words, concrete body that the sulfate attack has progressed is considered to have the same condition as soil or seawater of external concrete. The model proposed by Atkinson and Hearne represents the degradation process dominated by the reaction and the degradation rate of concrete due to sulfate ions is expressed in equation (5).

$$
R=\frac{X_{\text {spall }}}{t_{\text {spall }}}=\frac{E B^{2} c_{0} C_{E} D_{i}}{\alpha \gamma(1-v)}
$$

where,

$c_{0}$ : concentration of sulfate in solution $\left(\mathrm{mol} / \mathrm{m}^{3}\right)$

$C_{E}$ : concentration of sulfate reacting to ettringite $\left(\mathrm{mol} / \mathrm{m}^{3}\right)$

$D_{i}$ : diffusion coefficient of sulfate ions in concrete $\left(\mathrm{m}^{2} / \mathrm{s}\right)$

$E$ : elastic modulus (20GPa)

$R$ : degradation rate of concrete by sulfate ions $(\mathrm{mm} / \mathrm{sec})$ $\alpha$ : roughness factor of the area occurring degradation (assumed 1.0)

$B$ : stress of $1 \mathrm{~mol}$ sulfate to react in $1 \mathrm{~m} 3\left(1.8 \times 10^{-6} \mathrm{~m}^{3} / \mathrm{mol}\right)$ $\gamma$ : energy required to destroy concrete surface $\left(10 \mathrm{~J} / \mathrm{m}^{2}\right)$

$v$ : Poisson ratio $(0.2)$

\section{B. Calculation of $C_{E}$}

The amount of concentration of sulfate reacting to ettringite, referred to as $\mathrm{C}_{\mathrm{E}}$, can be obtained exactly from the chemical composition of cement or from experiments. To experimentally obtain the value of $\mathrm{C}_{\mathrm{E}}$, relationship that the amount of sulfate reacting with unit amount of hydrated cement is inversely proportional to the elapsed time and $\log$ curve, is available in a graph. This data is shown in the following equation.

$$
m=m_{o} \log _{10}\left(\frac{t_{c}}{t_{r} C_{k}}\right)
$$

where,

$m$ : amount of sulfate reacting with cement $(\mathrm{mol} / \mathrm{kg})$

$m_{e}$ : value of $\mathrm{m}$ to react completely $(\mathrm{mol} / \mathrm{kg})$

OPC: 1.24 , V-Cement: 1.07

$m_{o}$ : constant for m, OPC: 0.32 , V-Cement: 0.16

$t_{r}$ : time it takes to react (s), OPC: 3577, V-Cement: 1555

$c_{k}$ : concentration of sulfate ions in a kinetics experiment $\left(\mathrm{mol} / \mathrm{m}^{3}\right)$

Here, $m$ is the molar amount of sulfate reacting with cement, $m_{o}$ is the coefficient of regression analysis, $t$ is the time, $c$ is the concentration of sulfate in solution, $t_{r}$ is certain time to take the reaction, and $\mathrm{ck}$ is the concentration of sulfate ions in a kinetics experiment. The maximum value of $\mathrm{m}$ can be calculated from the initial amount of $\mathrm{C}_{3} \mathrm{~A}$ in cement. If the maximum value is represented as $\mathrm{mc}$, then the value of $\mathrm{t}$ for $\mathrm{m}=\mathrm{m}_{\mathrm{c}}$ corresponds to the value in $t=t_{\infty}$ for which the amount of $\mathrm{C}_{3} \mathrm{~A}$ is completely consumed. For $t_{\text {spall }}<t_{\infty}, \mathrm{C}_{\mathrm{E}}$ should be obtained from equations 129 and 130 . However, relationship of $t_{\text {spall }}>t_{\infty}$ is mostly shown in OPC and $\mathrm{C}_{\mathrm{E}}$ can be calculated by the amount of $\mathrm{C}_{3} \mathrm{~A}$ of cement because the amount of sulfate supplied to the external concrete is assumed to be constant, As $1 \mathrm{~mol}$ of $\mathrm{Al}_{2} \mathrm{O}_{3}$ is needed to produce $1 \mathrm{~mol}$ of ettringite, it is shown that the molar concentration of $\mathrm{Al}_{2} \mathrm{O}_{3}$ corresponds to the molar concentration of ettringite. Thus, the amount of cement $\left(x_{\text {cem }}\right)$ per $1 \mathrm{~m}^{3}$ concrete in given concrete mix proportion and the molar amount of ettringite $C_{E}$ formed in $1 \mathrm{~m} 3$ concrete out of the amount of aluminum oxide $\left(\phi \mathrm{Al}_{2} \mathrm{O}_{3}\right)$, can be obtained from equation (7).

$$
C_{E}=\frac{x_{c e m} \phi_{\mathrm{Al}_{2} O_{3}}}{0.10196}
$$

where,

$x_{\text {cem }}$ : amount of cement per $1 \mathrm{~m} 3$ concrete $\left(\mathrm{kg} / \mathrm{m}^{3}\right)$

$\phi \mathrm{Al}_{2} \mathrm{O}_{3}$ : : amount of aluminum oxide of cement (\%)

0.10196: weight of $1 \mathrm{~mol}$ of $\mathrm{Al}_{2} \mathrm{O}_{3}(\mathrm{~kg} / \mathrm{mol})$

As a result, the basic model can be expressed as follows.

$$
R=\frac{X_{\text {spall }}}{t_{\text {spall }}}=\frac{E B^{2} c_{0} D_{i} x \phi}{0.10196 \alpha \gamma(1-v)}
$$




\section{APPliCATION OF THE MODEL FOR SUlFATE ATTACK}

In this study, in order to predict the sulfate attack, the mechanistic model of Atkinson and Hearne is applied resulting in the equation below where the $\mathrm{C}_{\mathrm{E}}$ term is converted to the unit amount of cement $\mathrm{x}$ and the amount of $\phi \mathrm{Al}_{2} \mathrm{O}_{3}$.

$$
R=\frac{X_{\text {spall }}}{t_{\text {spall }}}=\frac{E B^{2} c_{0} D_{i} x \phi}{0.10196 \alpha \gamma(1-v)}(\mathrm{mm} / \mathrm{sec})
$$

\section{A. Data for Estimating Sulfate Attack}

Data to estimate the degree of sulfate attack is shown in the table below. The concentration of sulfate, $\mathrm{C}_{\mathrm{o}}$ in the exterior of given concrete structure of $0 \sim 25 \mathrm{~mol} / \mathrm{m}^{3}$ and the diffusion coefficient of $0 \sim 4 \times 10^{-12} \mathrm{~m}^{2} / \mathrm{sec}$ were given to calculate overall rate of attack depending on the concentration of sulfate and the diffusion coefficient, and for elastic modulus, roughness factor, stress of $1 \mathrm{~mol}$ sulfate per $1 \mathrm{~m}^{3}$, energy needed to destroy the concrete surface, and Poisson ratio, default values were used. Also, the unit amount of cement was $284 \mathrm{~kg} / \mathrm{m}^{3}$ after applying the mix proportion of design strength 4000psi used in the experiments for this study, and referred to the amount of aluminum oxide was $5 \%$ which was also the amount of OPC. Also, based on the composition analysis of domestic coastal seawater in the table, the upper limit of basic analysis range for the concentration of sulfate was determined. As shown in the table below, for the east coast in domestic coastal seawater, magnesium sulfate $\left(\mathrm{MgSO}_{4}\right)$ was shown to be $2.168 \mathrm{~g} / \mathrm{l}$, and calcium sulfate $\left(\mathrm{CaSO}_{4}\right)$ to be $1.491 \mathrm{~g} / \mathrm{l}$ and potassium sulfate was $0.863 \mathrm{~g} / \mathrm{l}$ based on the west coast seawater. Calculating the amount of sulfate in seawater, the molar concentration of sulfate for the east coast seawater is $0.0339 \mathrm{M}$ which corresponds to $35 \mathrm{~mol} / \mathrm{m}^{3}$.

\section{B. Rate of Attack by Diffusion Coefficient}

Fig.1 shows the relationship between the rate of sulfate attack and the change in diffusion coefficient for each concentration of sulfate in the external concrete, 5, 10, 15, 20, $25,30,35 \mathrm{~mol} / \mathrm{m}^{3}$, respectively, In the figure, the rate of sulfate attack is shown to increase as the concentration of sulfate increases. For $35 \mathrm{~mol} / \mathrm{m}^{3}$ of the concentration of sulfate, the amount of sulfate in seawater was expressed in $\mathrm{mol} / \mathrm{m}^{3}$ on the basis of the components of seawater, which indicates the attack that concrete directly adjoining to seawater can get. The result also means that high diffusion coefficient can cause significant damage to the structure (for this condition, there may be attack up to $5 \mathrm{~mm}$ in a year). In other words, on the condition that seawater is adjoining, if the diffusion coefficient is $4.0\left(\times 10^{-12} \mathrm{~m}^{2} / \mathrm{sec}\right)$, then the depth of damage due to the sulfate attack is $5 \mathrm{~mm}$ per year, and if the thickness of cover concrete for the given structure is $50 \mathrm{~mm}$, then the time it takes to completely damage the thickness of cover concrete is 10 years. Under the same condition, if the diffusion coefficient is $0.5\left(\times 10^{-12} \mathrm{~m}^{2} / \mathrm{sec}\right)$, then the rate of damage is $0.62 \mathrm{~mm}$ per year and the time it takes to completely damage the thickness of cover concrete is 80.6 years.

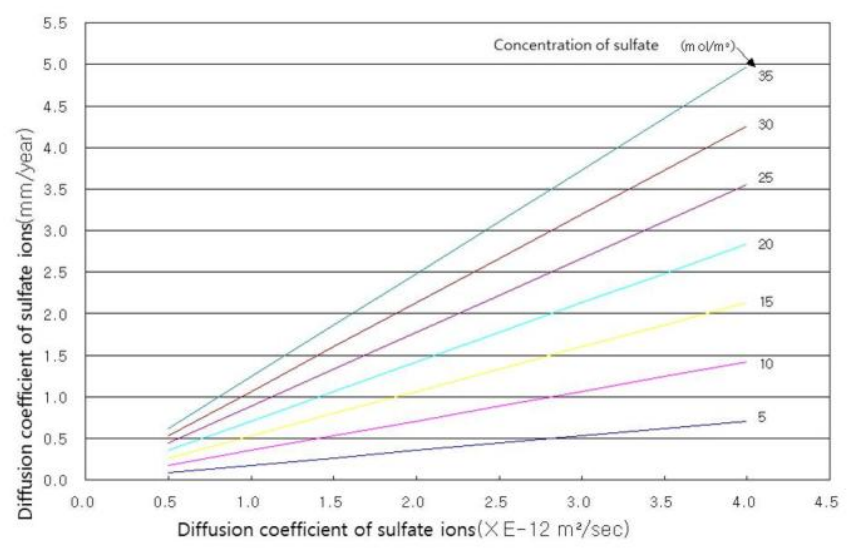

Fig. 1. Relationship between the rate of sulfate attack and the diffusion coefficient of sulfate ions for the concentration of sulfate

\section{Rate of Attack by ACI Criteria}

Fig. 2 shows the relationship between the rate of sulfate attack and the diffusion coefficient of sulfate ions for the case that the amount of water-soluble sulfate ions of the soil contacting with concrete is less than or equal to $0.1 \%$, according to the condition that are required for concrete exposed to sulfate of ACI Committee 201.2R and ACI Building Code 318R. In the figure, if the concentration of sulfate ions in groundwater is less than $150 \mathrm{ppm}(0.00156 \mathrm{M})$, then the environment is regarded as "Mild" or "Negligible" in which there is little or no influence of sulfate, about $1500 \mathrm{ppm}$ $(0.01561 \mathrm{M})$ as "Moderate" which has chance of sulfate attack, and about 10000ppm (0.10410M) as "Severe" which is in poor condition. As shown in the figure, for the case that the concentration of sulfate is about $150 \mathrm{ppm}$, there is little influence of sulfate, regardless of the diffusion coefficient. However, for the case of $10000 \mathrm{ppm}$, the rates of attack are shown to be $2.0 \mathrm{~mm} /$ year and $14 \mathrm{~mm} /$ year under $0.5\left(\times 10^{-12}\right.$ $\left.\mathrm{m}^{2} / \mathrm{sec}\right)$ and $4\left(\times 10^{-12} \mathrm{~m}^{2} / \mathrm{sec}\right)$, respectively, of diffusion coefficient, that means the diffusion coefficient of sulfate ions greatly influences the environment. The result shown in the figure for $1500 \mathrm{ppm}$ of the concentration of sulfate which belongs to "Moderate" condition appears to be the same for $15.6 \mathrm{~mol} / \mathrm{m}^{3}$ of the concentration of sulfate.



Fig. 2. The rate of attack according to ACI criteria for the concentration of sulfate

\section{Comparison of Existing Models}

Of the existing models, the empirical model of Atkinson \& 
Hearne, the empirical model of Shuman, and mechanistic model of Atkinson \& Hearne were compared by the depth of attack for the range of age and the results were represented in Fig. 3.

As shown in Fig. 3, the depth of attack appeared to be different in the order of the empirical model of Atkinson \& Hearne $>$ the mechanistic model of Atkinson \& Hearne $>$ the empirical model of Shuman. The reason that estimation of sulfate attack by the empirical model of Shuman appeared to be significantly lower than by other models is because the diffusion coefficient used to configure the model of Shuman was fairly different from the value used for the comparison. Also, the depth of sulfate attack in age of 100 for the empirical model of Atkinson \& Hearne shows approximately $60 \%$ higher value compared to the mechanistic model.

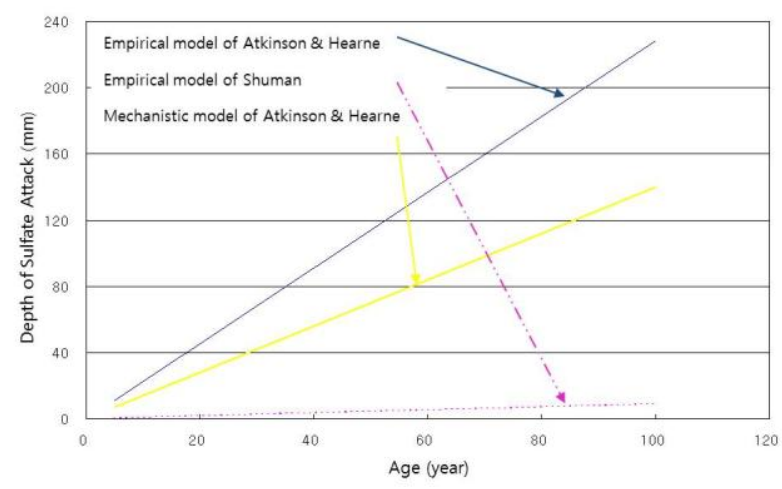

Fig. 3. Comparison of the rate of attack for each model

\section{ACKNOWLEDGMENT}

This work was supported by the Nuclear Research \& Development of the Korea Institute of Energy Technology Evaluation and Planning (KETEP) grant funded by the Korea government Ministry of Knowledge Economy. (No. 2011T100200161)

\section{REFERENCES}

[1] Standard Practice for Developing Accelerated Tests to Aid Prediction of the Service Life of Building Components and Materials, ASTM Designation E 632.

[2] P. K. Mehta, "Mechanisms of Sulfate Attack on Portland Cement Concrete Anonther Look," Cement and Concrete Research, vol. 13, pp. 401-406, 1983

[3] M. Uysal, "The influence of coarse aggregate type on mechanical properties of fly ash additive self-compacting concrete," Construction and Building Materials, vol. 37, pp. 533-540
[4] M. Maali, H. Showkati, and S. M. Fatemi, "Investigation of the buckling behavior of conical shells under weld-induced imperfections," Thin-Walled Structures, vol. 57, pp. 13-24.

[5] J. Gao, Z. Yu, L. Song, T. Wang, and S. Wei, "Durability of concrete exposed to sulfate attack under flexural loading and drying-wetting cycles," Construction and Building Materials, vol. 39, pp. 33-38,

[6] A. Kanellopoulos, M. F. Petrou, and I. Ioannou, "Durability performance of self-compacting concrete," Construction and Building Materials, vol. 37, pp. 320-325.

[7] A. Leemann, P. Lura, and R. Loser, "Shrinkage and creep of SCC - The influence of paste volume and binder composition," Construction and Building Materials, vol. 25, Issue 5, pp. 2283-2289

[8] J. Y. Petit, E. Wirquin, Y. Vanhove, and K. Khayat, "Yield stress and viscosity equations for mortars and self-consolidating concrete," Cement and Concrete Research, vol. 37, Issue 5, pp. 655-670

[9] X. Gao, S. Kawashima, X. Liu, and S. P. Shah, "Influence of clays on the shrinkage and cracking tendency of SCC," Cement and Concrete Composites, vol. 34, Issue 4, pp. 478-485,

[10] F. Aslani and S. Nejadi, "Mechanical properties of conventional and self-compacting concrete: An analytical study," Construction and Building Materials, vol. 36, pp. 330-347

[11] D. Yang and J. Luo, "The damage of concrete under flexural loading and salt solution," Construction and Building Materials, vol. 36, pp. 129-134.

[12] A. A. A. Hassan, K. M. A. Hossain, and M. Lachemi, "Bond strength of deformed bars in large reinforced concrete members cast with industrial self-consolidating concrete mixture," Construction and Building Materials, vol. 24, pp. 520-530

[13] H. A. Mesbah, A. Yahia, and K. H. Khayat, "Electrical conductivity method to assess static stability of self-consolidating concrete," Cement and Concrete Research, vol. 41, pp. 451-458

Ho Jae Lee is a researcher in Structural Research Division, Korea Institute of Construction Technology(KICT), Republic of Korea. He received his BSc in Suwon University, Republic of Korea, MSc in Yonsei University, Republic of Korea. His research interest covers cement chemistry, corrosion of steel in concrete and its quantitative evaluation.

Myung-Sug Cho is a research fellow in the Plant Construction \& Engineering Laboratory, KHNP Central Research Institute, Korea Hydro \& Nuclear Power Co., LTD, South Korea. His research interest covers high performance concrete development and seismic engineering of Nuclear Power Plant structures.

Jong-Suk Lee is a senior researcher in Structural Engineering Research Division, Korea Institute of Construction Technology(KICT), Republic of Korea. He received his BSc, MSc and PhD in Hanyang University, Republic of Korea. His research concerns the durability of NPP(Nuclear Power Plant) concrete structures, structural analysis of concrete structure.

Do Gyeum Kim is a research fellow in Structural Engineering Research Division, Korea Institute of Construction Technology(KICT), Republic of Korea. He received his BSc, MSc and PhD in Chungnam National University, Republic of Korea. His research concerns the durability of concrete structures in terms of corrosion of steel in concrete, ionic transport and microstructure analysis of concrete. 